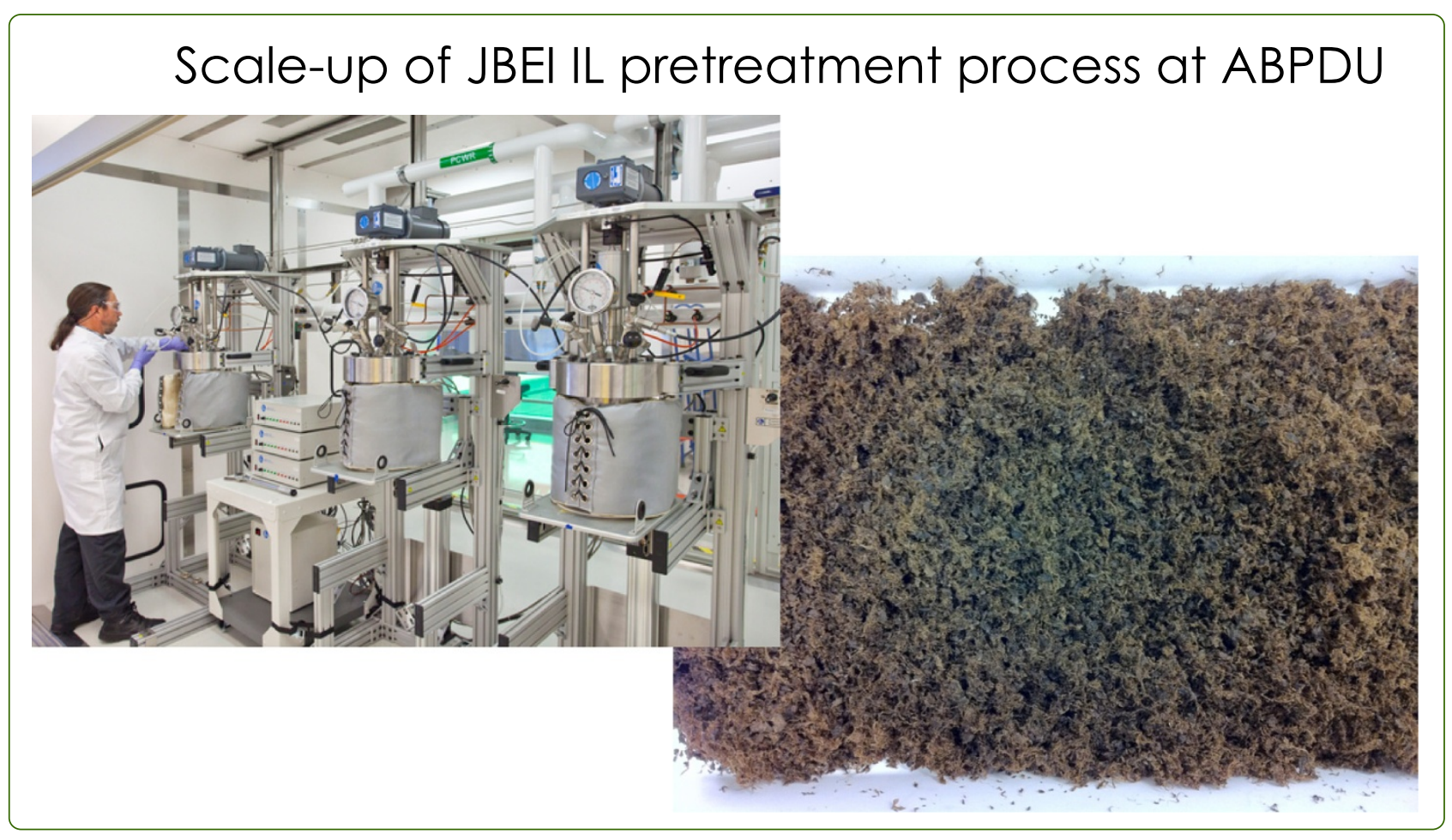

\title{
Scale-up and evaluation of high solid ionic liquid pretreatment and enzymatic hydrolysis of switchgrass
}

Li et al. 


\title{
Scale-up and evaluation of high solid ionic liquid pretreatment and enzymatic hydrolysis of switchgrass
}

Chenlin $\mathrm{Li}^{1}$, Deepti Tanjore ${ }^{1}$, Wei He ${ }^{1}$, Jessica Wong ${ }^{1}$, James $\mathrm{L}$ Gardner $^{1}$, Kenneth $\mathrm{L}$ Sale ${ }^{2,3}$, Blake A Simmons ${ }^{2,3}$ and Seema Singh ${ }^{2,3^{*}}$

\begin{abstract}
Background: Ionic liquid (IL) pretreatment is receiving significant attention as a potential process that enables fractionation of lignocellulosic biomass and produces high yields of fermentable sugars suitable for the production of renewable fuels. However, successful optimization and scale up of IL pretreatment involves challenges, such as high solids loading, biomass handling and transfer, washing of pretreated solids and formation of inhibitors, which are not addressed during the development stages at the small scale in a laboratory environment. As a first in the research community, the Joint BioEnergy Institute, in collaboration with the Advanced Biofuels Process Demonstration Unit, a Department of Energy funded facility that supports academic and industrial entities in scaling their novel biofuels enabling technologies, have performed benchmark studies to identify key challenges associated with IL pretreatment using 1-ethyl-3-methylimidazolium acetate and subsequent enzymatic saccharification beyond bench scale.

Results: Using switchgrass as the model feedstock, we have successfully executed 600-fold, relative to the bench scale $(6 \mathrm{~L}$ vs $0.01 \mathrm{~L})$, scale-up of IL pretreatment at 15\% (w/w) biomass loading. Results show that IL pretreatment at $15 \%$ biomass generates a product containing $87.5 \%$ of glucan, $42.6 \%$ of xylan and only $22.8 \%$ of lignin relative to the starting material. The pretreated biomass is efficiently converted into monosaccharides during subsequent enzymatic hydrolysis at 10\% loading over a 150-fold scale of operations (1.5 L vs $0.01 \mathrm{~L}$ ) with $99.8 \%$ fermentable sugar conversion. The yield of glucose and xylose in the liquid streams were $94.8 \%$ and $62.2 \%$, respectively, and the hydrolysate generated contains high titers of fermentable sugars ( $62.1 \mathrm{~g} / \mathrm{L}$ of glucose and $5.4 \mathrm{~g} / \mathrm{L}$ cellobiose). The overall glucan and xylan balance from pretreatment and saccharification were $95.0 \%$ and $77.1 \%$, respectively. Enzymatic inhibition by $\left[\mathrm{C}_{2} \mathrm{mim}\right][\mathrm{OAc}]$ at high solids loadings requires further process optimization to obtain higher yields of fermentable sugars.

Conclusion: Results from this initial scale up evaluation indicate that the IL-based conversion technology can be effectively scaled to larger operations and the current study establishes the first scaling parameters for this conversion pathway but several issues must be addressed before a commercially viable technology can be realized, most notably reduction in water consumption and efficient IL recycle.
\end{abstract}

Keywords: Scale-up, Pretreatment, Saccharification, Ionic liquid, High solid loading, Viscosity, Inhibition

\footnotetext{
* Correspondence: seesing@sandia.gov

${ }^{2}$ Deconstruction Division, Joint BioEnergy Institute, Emeryville, CA, USA

${ }^{3}$ Biological and Materials Science Center, Sandia National Laboratories,

Livermore, CA, USA

Full list of author information is available at the end of the article
}

\section{Biomed Central}

(c) 2013 Li et al.; licensee BioMed Central Ltd. This is an open access article distributed under the terms of the Creative Commons Attribution License (http://creativecommons.org/licenses/by/2.0), which permits unrestricted use, distribution, and reproduction in any medium, provided the original work is properly cited. 


\section{Background}

The state of technology for the conversion of agricultural residues, perennial grasses, woody perennials and forest products for the production of biofuels is rapidly advancing $[1,2]$. Production of clean fermentable sugars for biofuel production requires pretreating the biomass to overcome the recalcitrance of lignocellulose and render the polysaccharides within the plant cell walls amenable to enzymatic saccharification [2-5]. Among the leading pretreatment technologies, certain ionic liquids (ILs) have recently been shown to efficiently fractionate biomass and provide clean sugar substrate for the production of ethanol and other advanced biofuels [6-11].

Previous work has illustrated several favorable properties of IL pretreatment for biomass deconstruction at the laboratory scale. These include efficient biomass dissolution and disruption, reduced cellulose crystallinity and lignin content in the recovered product, enhanced biomass saccharification, and low toxicity and environmental impact [7,9-15]. However, most of the IL pretreatment data to date were obtained at low solid loading (3-10\%) and at the 10 to $50 \mathrm{~mL}$ level of operation [16-18], which cannot be directly translated to industrially relevant scales. Thus, liter-scale experiments are a necessary intermediate step between bench- and pilot-scale in order to identify operational parameters and potential problems associated with scale-up prior to pilot-scale and full-scale commercial operations. This is especially true as IL pretreatment is a relatively new pretreatment technology and no scale-up systems have been described in the scientific literature.

The advantages of using high-solid loadings $(\geq 15 \%)$ in the unit operations of lignocellulose conversion include increased sugar and ethanol concentrations and decreased production and capital cost [4]. However using high-solids in the IL process at large-scale is still relatively unexplored, and more research is required to overcome certain challenges, including high quantity materials handling, equipment mass transfer limitations, rheological problems, and solvent usage for washing, that are not as apparent at low solids loadings. In addition, high solid enzymatic saccharification has been suggested to increase the initial conversion rate and final fermentable sugar concentrations [19], but can exacerbate enzyme inhibition and pose rheological challenges that must be taken into account. Cellulase and hemicellulase inhibitors include products such as glucose and xylose, intermediates such as cellobiose, degradation products arising from pretreatment, solvents such as IL and ethanol (the latter used for precipitation or washing, as well as lignin due to nonspecific binding and solubilized phenolics) [20-23]. Detoxification of lignocellulosic hydrolysates via biological, chemical and physical conditioning processes have been used to remove inhibitors prior to or after enzymatic hydrolysis [23,24]. For IL pretreatment, post-washing of recovered materials with water or other solvents to dilute the IL to non-inhibitory levels and to remove other biomass-derived products has been investigated [20,22]. Other options include developing IL-tolerant enzymes and microorganisms to conduct single pot configuration for enzyme hydrolysis and microbial fermentation [25,26], or using lower IL concentration (20-50\%, w/v) in water to pretreat biomass and potentially reduce the amount of washing required prior to enzymatic saccharification [21,27]. To date, all these potential alternatives have been limited to the lab-scale level of development and require more investigation before scale-up can occur.

As a first in the research community, the Joint BioEnergy Institute (JBEI), in collaboration with the Advanced Biofuels Process Demonstration Unit (ABPDU), a Department of Energy (DOE)-funded facility that supports academic and industrial entities in scaling their novel technologies, have performed benchmark studies to identify the key large-scale process issues associated with IL pretreatment and subsequent saccharification. Building on the small scale optimization data, the scope of the current study encompasses the following aims relevant to assessing IL pretreatment for biofuel production: 1) evaluating IL pretreatment and subsequent enzymatic saccharification for high-solids loading at liter scales; 2) understanding the rheological properties of IL pretreated biomass that affect material handling during process integration; 3) identifying the critical requirements of the washing unit operation to minimize inhibition; 4) tracking the material and energy flow for product/solvent and energy recovery.

\section{Results and discussion \\ Scale up of IL pretreatment}

Certain ILs, such as 1-ethyl-3-methylimidaolzium acetate $\left(\left[\mathrm{C}_{2} \mathrm{mim}\right][\mathrm{OAc}]\right)$, can dissolve a wide range of feedstocks at solids loadings less than $5 \%(\mathrm{w} / \mathrm{w})([9,16]$. However, the large amounts of relatively expensive $\left.\left[\mathrm{C}_{2} \mathrm{mim}\right][\mathrm{OAc}]\right)$ required for effective reduction of biomass recalcitrance to improve subsequent rates and yields of enzymatic hydrolysis is a major concern [18]. Thus, higher solid loadings that require lower volumes of IL/water/solvent and smaller reactors would reduce capital and production costs and would be a significant step toward practical lignocellulosic IL pretreatment strategies [4,10,18,28].

For the current study, $0.9 \mathrm{~kg}$ of milled switchgrass was mixed with $\left[\mathrm{C}_{2} \mathrm{mim}\right][\mathrm{OAc}]$ and processed at $6 \mathrm{~L}$ scale at a solid loading of $15 \%(\mathrm{w} / \mathrm{w})$ in a $10 \mathrm{~L}$ Parr reactor. Figure 1 presents the biomass morphologies at different stages of the IL pretreatment process. At this solid loading, switchgrass was observed to be significantly solubilized in $\left[\mathrm{C}_{2} \mathrm{mim}\right][\mathrm{OAc}]$ after $3 \mathrm{~h}$ reaction at $160^{\circ} \mathrm{C}$, which is similar to that observed at lower solid loading in $10 \mathrm{~mL}$ small- 

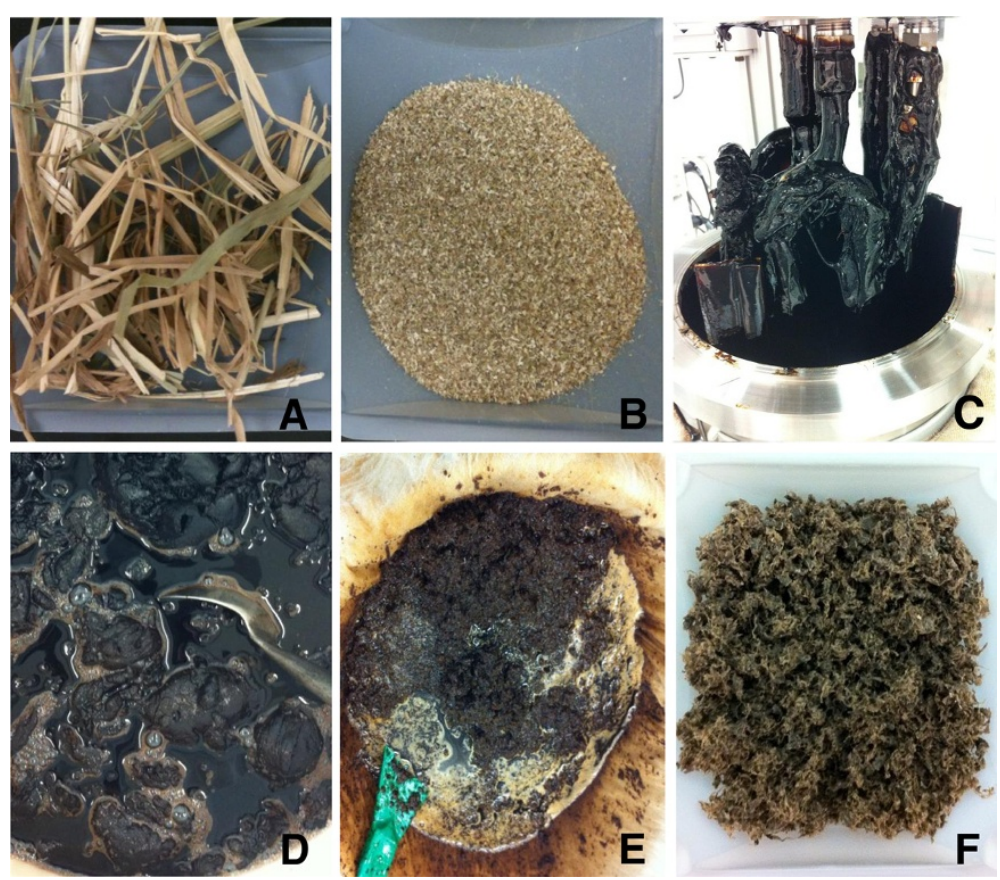

Figure $1\left[\mathrm{C}_{2} \mathrm{mim}\right][\mathrm{OAc}]$ pretreatment of switchgrass at $6 \mathrm{~L}$ scale. Images depicting (A) switchgrass straw, (B) switchgrass flour after size reduction (2 $\mathrm{mm}$ screen), (C) expansion and solubilization of switchgrass in $\left[\mathrm{C}_{2} \mathrm{mim}\right][\mathrm{OAc}]$ after $3 \mathrm{~h}$ reaction at $160^{\circ} \mathrm{C}$, (D) gel formation upon water precipitation, $\mathbf{( E )}$ homogenized biomass undergoing washing process and $\mathbf{F}$ ) recovered switchgrass.

scale studies $[15,20]$. We attribute this finding to the effective and uniform mixing provided by the anchor impeller. Unlike other pretreatment methods that preserve the fibrous structure of the biomass in the slurry $[4,29]$, the switchgrass/IL mixture has a morphology that is highly viscous with no visible signs of fibrous material remaining (Figure 1C).

Figure 1D depicts the formation of a gel phase when water is added into the $\left[\mathrm{C}_{2} \mathrm{mim}\right][\mathrm{OAc}]$-switchgrass slurry. This has been observed at biomass loadings as low as $3 \%$ $(\mathrm{w} / \mathrm{w})$ and has several consequences [20,30]. First, mixing gel phases, which are quite stiff at high solid loadings, can be problematic. Second, if the gel phase is not completely dispersed in the solvents, separation of precipitated solids from the IL is more difficult and may result in increased losses of the IL and exacerbated toxicity to downstream saccharification and fermentation processes utilizing enzymes and microorganisms [22]. Many reports in the literature on IL pretreatment utilize low biomass loadings of 3-5\% and large quantities of precipitating solvent or use mixtures of acetone and alcohol for precipitation and washing $[7,9,11,20]$. These practices minimize the formation of the gel phase but increase solvent consumption and other processing costs. In light of these observations, we chose water as the precipitating and main washing solvent due to its cost and relative ease of use. The gel materials were homogenized with a laboratory blender to mechanically break down the gel and facilitate complete dispersion in water.

The efficient recovery of pretreated materials is an important unit operation in all pretreatment techniques. Similarly, the efficient recovery of pretreated biomass and removal of residual solutes is a key step in the scaledup IL process. In this study, after precipitation and homogenization, the biomass went through $3 \times$ water, $1 \times$ ethanol, $2 \times$ ethanol/water and 1 final water washing steps (Figure 1E) to obtain clean pretreated switchgrass that is readily saccharified to fermentable sugars. After precipitation, extensive washing and filtration, the wet recovered switchgrass displays a porous structure (Figure 1F). Smallscale studies commonly use dried pretreated materials for physiochemical characterization and low loading levels for saccharification $[6,11,15,16]$. Drying might greatly change the characteristics of cellulosic materials. For example, air drying reduces substrate reactivity due to collapse of the supramolecular structure, whereas freeze drying better preserves the substrate morphology but still decreases the substrate accessibility compared to the samples that were never dried [29]. Enzymatic hydrolysis of cellulose requires hydrated conditions and in practice drying of materials may not be desired in a biorefinery that continuously requires substrate for fermentation. Thus, a unit operation for material drying was not employed in this process development and all pretreated materials were kept wet and stored at $4^{\circ} \mathrm{C}$ before enzymatic saccharification. 


\section{Viscosity of $\left[\mathrm{C}_{2} \mathrm{mim}\right][\mathrm{OAc}]$ pretreated materials}

At high solids, lignocellulosic biomass is typically fibrous and hygroscopic and requires special mixing and handling techniques at large-scale. Rheology of biomass can significantly influence the progress of chemical and biological conversion of biomass to monomeric sugars [31]. Rheological measurements have been conducted to investigate the behavior of dilute acid pretreated softwood [32] and corn stover [31,33], but very limited studies have been devoted to the rheological characteristics of IL pretreated lignocellulosic feedstocks [28]. In this study, we measured the rheological properties of the switchgrass slurry before pretreatment $(15 \% \mathrm{w} / \mathrm{w}$ insoluble solids in $\left.\left[\mathrm{C}_{2} \mathrm{mim}\right][\mathrm{OAc}]\right)$, after pretreatment $(15 \% \mathrm{w} / \mathrm{w}$ insoluble solids in $\left.\left[\mathrm{C}_{2} \mathrm{mim}\right][\mathrm{OAc}]\right)$, and after washing $(12 \% \mathrm{w} / \mathrm{w}$ insoluble solids in water). The elastic (or storage) moduli (G', Pa), viscous (or loss) moduli (G", Pa), and complex viscosities $\left(\eta^{*}, \mathrm{~Pa} \cdot \mathrm{s}\right)$ within a frequency range of 0.1 to $100 \mathrm{~Hz}$ at a constant stress of $10 \mathrm{~Pa}$ were measured and shown in Figure 2. The three viscoelastic parameters, $\eta^{*}$ $\left(10^{4}\right.$ to $\left.10^{2} \mathrm{~Pa} \cdot \mathrm{s}\right), \mathrm{G}^{\prime}\left(5 \times 10^{4} \mathrm{~Pa}\right)$, and G" $\left(5 \times 10^{3} \mathrm{~Pa}\right)$, obtained from switchgrass $/\left[\mathrm{C}_{2} \mathrm{mim}\right][\mathrm{OAc}]$ mixtures after pretreatment were similar to those reported for dilute acid pretreated corn stover $(20 \% \mathrm{w} / \mathrm{w}$ insoluble solids) [31], indicating that both pretreatment technologies have a similar influence on the rheological properties of biomass. These results are interesting because $\left[\mathrm{C}_{2} \mathrm{mim}\right][\mathrm{OAc}]$ has a much higher viscosity $\left(9.3 \times 10^{-2} \mathrm{~Pa} \cdot \mathrm{s}\right)$ than water $\left(1 \times 10^{-3} \mathrm{~Pa} \cdot \mathrm{s}\right)$ at $25^{\circ} \mathrm{C}$. The high viscosity of $\left[\mathrm{C}_{2} \mathrm{mim}\right]$ [OAc] didn't increase the viscosity of biomass-ionic liquid mixture and possibly led to a reduced requirement of mixing due to improved solvation of biomass. A recent study reported rheological properties of $\left[\mathrm{C}_{2} \mathrm{mim}\right][\mathrm{OAc}]$ pretreated switchgrass at the $10 \mathrm{~mL}$ scale, where biomass was only pre-mixed with $\left[\mathrm{C}_{2} \mathrm{mim}\right][\mathrm{OAc}]$ prior to the pretreatment but not throughout the process [28]. Interestingly, the shear thinning behavior and viscoelastic properties of the pretreated biomass from this $10 \mathrm{~mL}$ scale were similar to the results obtained from this study at $6 \mathrm{~L}$ scale (Figure 2), where a Parr reactor system with continuously stirring at $50 \mathrm{rpm}$ was used.

To further evaluate the requirements of mixing and handling techniques for high solid loadings, it is critical to obtain a fundamental understanding of the biomass flow properties under various unit operations. In this study, we observed that the $\eta^{*}\left(5 \times 10^{5}\right.$ to $\left.10^{3} \mathrm{~Pa} \cdot \mathrm{s}\right)$ of switchgrass/IL slurry before pretreatment was almost 100-fold higher than that after pretreatment (Figure 2A and $2 \mathrm{~B})$. Washing effectively removed $\left[\mathrm{C}_{2} \mathrm{mim}\right][\mathrm{OAc}]$ and lignin, and also led to a significant drop in $\eta^{*}\left(5 \times 10^{1}\right.$ to $10^{-1} \mathrm{~Pa} \cdot \mathrm{s}$ ) (Figure 2C). This continuous decrease in viscosity from before pretreatment to after pretreatment and eventually after washing indicates that the unit operations of IL pretreatment and washing are capable of making

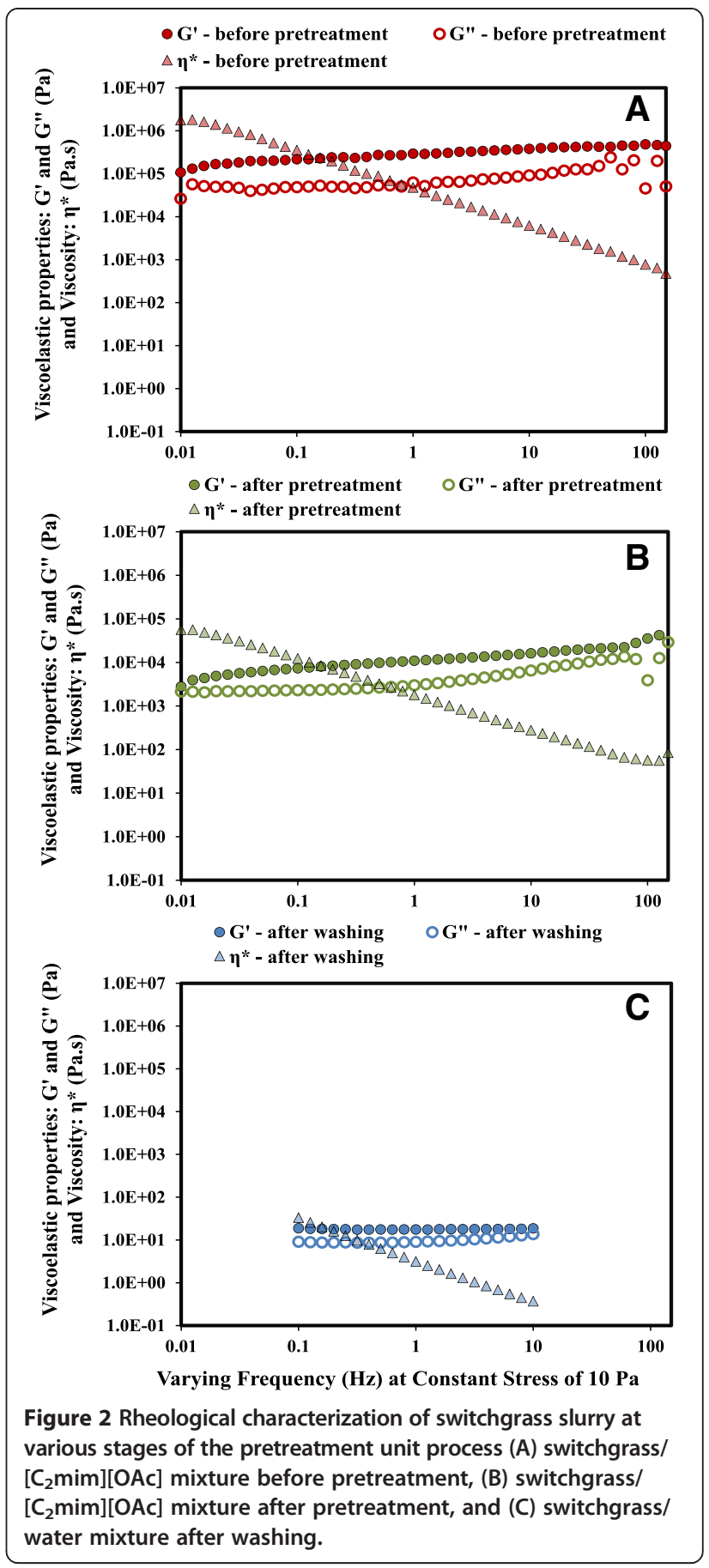

biomass more "fluid-like" and material handling more amenable in large-scale processes.

\section{Solids recovery and changes of chemical composition}

Based on the results of $6 \mathrm{~L}$ scale runs, $55.3 \%$ of the starting material was recovered as solids after pretreatment with $\left[\mathrm{C}_{2} \mathrm{mim}\right][\mathrm{OAc}]$. This amount of solids recovered at the $6 \mathrm{~L}$ scale is similar to previous value of $49.3 \%$ for switchgrasss pretreated at $3 \%(\mathrm{w} / \mathrm{w})$ loading at the $10 \mathrm{~mL}$ 
scale [16], suggesting that solids recovery is comparable with scaling to higher biomass loadings and larger volumes. The slight differences observed are likely attributed to the solid loading, mixing and cellulose regeneration method at the larger scale. Similarly, a recent study obtained a higher solid recovery of $64.9 \%$ from mixed feedstocks under the same reaction conditions but at $10 \%$ biomass loading at the $200 \mathrm{~mL}$ scale [17]. The mass loss is attributed to the solubilization of components such as $x y-$ lan, lignin and other extractives during pretreatment with $\left[\mathrm{C}_{2} \mathrm{mim}\right][\mathrm{OAc}]$, and it should be noted that there are processes in place to recover the solubilized sugars and are not considered lost to the overall conversion process $[34,35]$. Our recent lab scale study has demonstrated that the application of liquid-liquid extraction achieved over $90 \%$ glucose and xylose recovery from $\left[\mathrm{C}_{2} \mathrm{mim}\right][\mathrm{OAc}]$ water mixture, whereas lignin was fractionated into streams with different molecular weight after pretreatment and saccharification, offering the possibility for lignin recovery and subsequent valorization [26,35].

Figure 3 illustrates the scale-up and loading effects on the changes of three major biomass components, glucan, xylan and lignin, of pretreated switchgrass in comparison to the results obtained at the $10 \mathrm{~mL}$ scale data from previous studies [7]. Unlike the significant removal of both xylan and lignin observed at $10 \mathrm{~mL}$ scale and 3\% solids loading, at the $6 \mathrm{~L}$ scale there is significantly less lignin content $(8.7 \%$ vs $13.2 \%)$ but much higher xylan content $(23.8 \%$ vs $7.6 \%)$. This is likely due to the loading used in the current study, and indicates that this process configuration favorably preserves the structural carbohydrates for subsequent enzymatic saccharification and fermentation.

\section{Hemicellulose in the liquid fractions}

IL pretreatment can remove significant amounts of hemicellulose and small quantities of amorphous cellulose depending on the severity of reaction conditions [15], and, under some pretreatment conditions, hemicellulose can be depolymerized to oligosaccharides [7]. To understand the effect of washing on hemicellulose removal, a complete analysis on sugar released during eight washing steps was conducted using High Performance Anion Exchange Chromatography (HPAEC) after trifluoroacetic acid (TFA) digestion (Figure 4). These results show that the pattern of hemicellulose release, as measured by the xylose, arabinose and galactose contents, depends on the washing steps and the solvent used. The second wash liquor removed much higher xylose $(21.4 \%)$, arabinose $(34.8 \%)$ and galactose content (27.8\%). This result is likely due to major fractions of three polymers still being bound to the solid in the first washing step and being released into the liquid when water was added for the 2nd wash. The third and fourth washes were also effective in removing the three sugars. The last water wash released more sugars than the previous ethanol and ethanol-water washes. This could be attributed to the ethanol wash steps $(5,6$ and 7$)$ that removed more IL and made hemicellulose less bound to the cellulose, and with the last water wash, the loosely bound hemicellulose readily dissolved into water. Small amounts of glucose were also observed in the first four water washes, which were likely released from the amorphous cellulose initially present in switchgrass. Results also show that the total loss of the initial glucan fraction in all the washing steps was $12.6 \%$ at $6 \mathrm{~L}$ scale, lower than the loss of $15.6 \%$ in previous small scale studies [16],

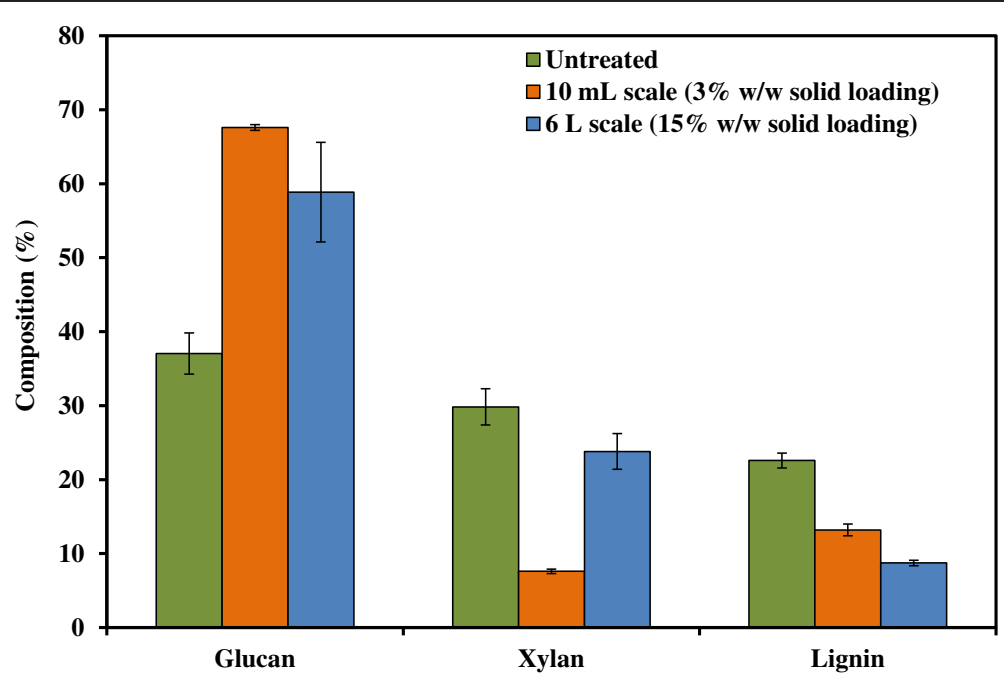

Figure 3 Comparison of compositional changes in switchgrass before and after pretreatment at $10 \mathrm{~mL}$ and $6 \mathrm{~L}$ scales. The $10 \mathrm{~mL} s c a l e$ data were taken from our previous study [7]. 


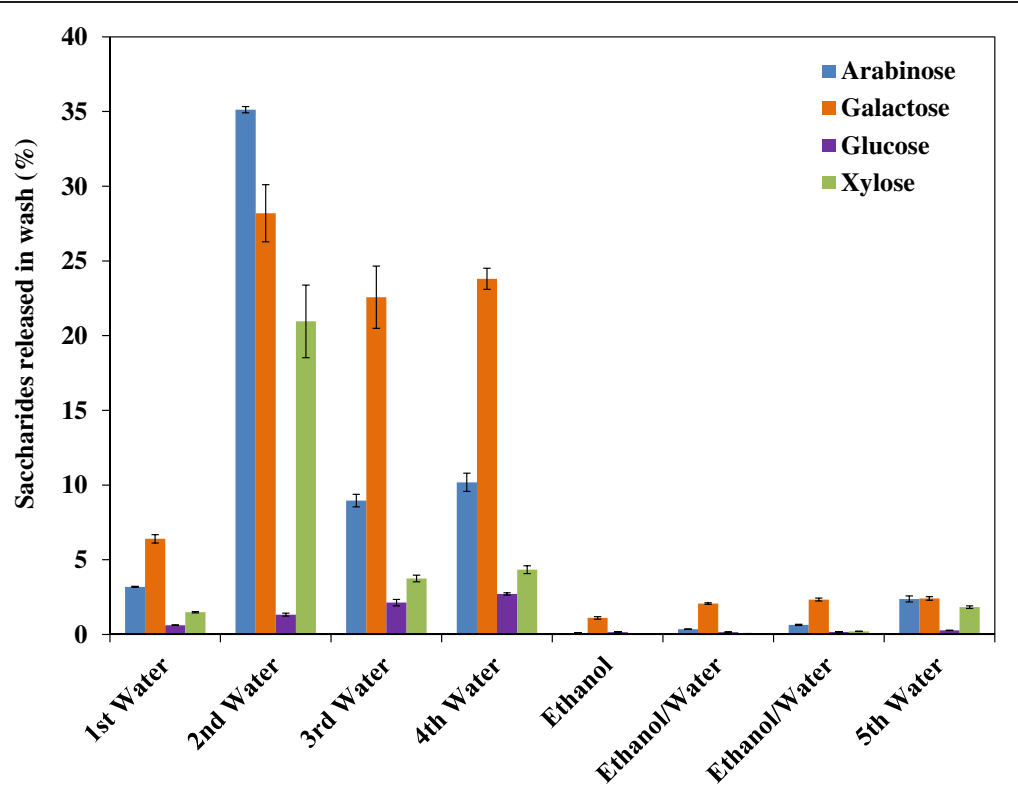

Figure 4 Pattern of saccharides released (based on untreated compositions) from $\left[\mathrm{C}_{2} \mathrm{mim}\right][\mathrm{OAc}]$ pretreated switchgrass into the liquid phase and its dependence on the number of washes.

further suggesting high solids loading may help retain the structural carbohydrates in the recovered solid stream.

\section{IL content and its impact on enzymatic saccharification}

Residual IL in the solids have been found to inhibit both commercial cellulases and microbial fermentation in Saccharomyces cerevisiae [22], requiring extensive washing after IL pretreatment. In this study, the $\left[\mathrm{C}_{2} \mathrm{mim}\right][\mathrm{OAc}]$ content in both the liquid and solid fractions was measured to track the efficiency of washing steps. As shown in Table 1, the amount of $\left[\mathrm{C}_{2} \mathrm{mim}\right][\mathrm{OAc}]$ in the liquid stream was significantly reduced from $43.43 \%(\mathrm{w} / \mathrm{v})$ after the first water wash to $0.03 \%(\mathrm{w} / \mathrm{v})$ after the final water wash. However, a certain amount of IL residue is hypothesized to stay in the solid fraction and may not be easily removed. To investigate the effects of $\left[\mathrm{C}_{2} \mathrm{mim}\right][\mathrm{OAc}]$ in the solid fraction on enzymatic saccharification, a separate

Table 1 Amount of $\left[C_{2}\right.$ mim][OAc] present as a function of the wash process

\begin{tabular}{ccc}
\hline Wash no. & Solvent & {$\left[\mathbf{C}_{\mathbf{2}}\right.$ mim] $[\mathbf{O A c}]$ content $(\%, \mathbf{w} / \mathbf{v})$} \\
\hline 1 & Water & $43.43 \pm 0.72$ \\
2 & Water & $7.56 \pm 0.15$ \\
3 & Water & $2.06 \pm 0.09$ \\
4 & Water & $0.48 \pm 0.02$ \\
5 & Ethanol & $0.20 \pm 0.01$ \\
6 & Ethanol/water & $0.12 \pm 0.01$ \\
7 & Ethanol/water & $0.06 \pm 0.00$ \\
8 & Water & $0.03 \pm 0.00$ \\
\hline
\end{tabular}

small-scale study was conducted to track the residual $\left[\mathrm{C}_{2} \mathrm{mim}\right][\mathrm{OAc}]$ remaining in the solids after pretreatment. Samples of the solids remaining after each water washing step were taken and completely solubilized using excess concentrations of Cellic ${ }^{\circ} \mathrm{HTec} 2$ and $\mathrm{CTec} 2$ for five days to liberate the $\left[\mathrm{C}_{2} \mathrm{mim}\right][\mathrm{OAc}]$. The $\left[\mathrm{C}_{2} \mathrm{mim}\right][\mathrm{OAc}]$ concentration in the liquid phase following complete solubilization was then used as a measure of the residual $\left[\mathrm{C}_{2} \mathrm{mim}\right][\mathrm{OAc}]$ in the solids at each wash step. In parallel, solid samples after each wash were hydrolyzed $(54 \mathrm{mg} / \mathrm{g}$ glucan of CTec2, $6 \mathrm{mg} / \mathrm{g}$ glucan $\mathrm{HTec} 2,50^{\circ} \mathrm{C}$, pH 5.5) for 72 hours to determine sugar yields. Figure 5 clearly shows that the reduction of IL in the solids as a function of the number of washes yields significant increases in sugar release. At $\left[\mathrm{C}_{2} \mathrm{mim}\right][\mathrm{OAc}]$ concentrations of $16.6-46.6 \%$, all sugar yields were less than $60 \%$, indicating the glycoside hydrolase enzymes in the commercial cocktails have reduced activity [25]. After the 4th water wash, all sugar yields in the hydrolysates reached $70-80 \%$ as the $\left[\mathrm{C}_{2} \mathrm{mim}\right]$ [OAc] concentration dropped to $5.7 \%$. After the final water wash, the inhibition on the sugar yields was not significant at the IL concentration of 3.5\%. Both Table 1 and Figure 5 do not show significant IL removal efficiency by ethanol washing steps as indicated by the slight decrease of $\left[\mathrm{C}_{2} \mathrm{mim}\right][\mathrm{OAc}]$ in liquid and solid streams. It is evident that this pretreatment configuration requires extensive washing of the biomass post-pretreatment to remove the residual $\left[\mathrm{C}_{2} \mathrm{mim}\right][\mathrm{OAc}]$, which is known to inhibit downstream saccharification and fermentation [22]. The excessive use of water and waste disposal associated with washing poses challenges for the scale-up of IL 


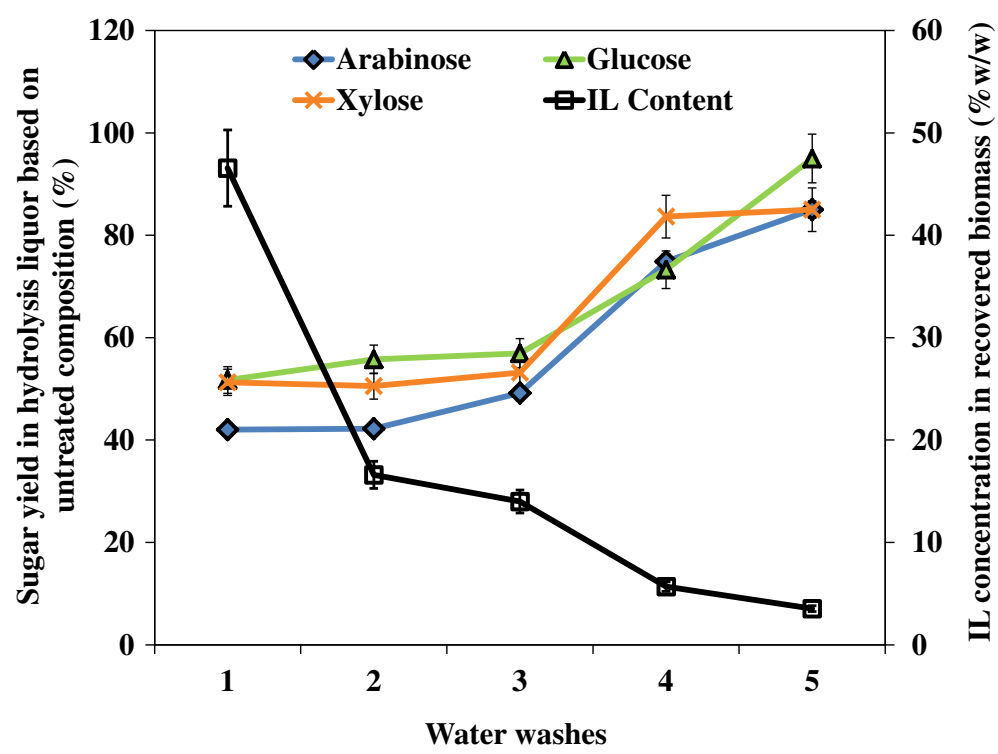

Figure 5 Impact of residual $\left[C_{2}\right.$ mim] [OAc] in terms of saccharification inhibition. Sugar yields were measured after saccharification (54 mg/g glucan of Cellic $\mathrm{CTec} 2,6 \mathrm{mg} / \mathrm{g}$ glucan Cellic HTec2, 50 $0^{\circ} \mathrm{C}$, pH 5.5 for 72 hours) of solids taken after each wash step. IL concentration in recovered biomass is the concentration of $\left[\mathrm{C}_{2} \mathrm{mim}\right][\mathrm{OAc}]$ measured in the supernatant after complete solubilization of the solids.

pretreatment technology. Alternative options to reduce water usage have been recently reported, including the development IL-tolerant cellulase cocktails (i.e., JTherm cocktail recently developed at JBEI) that are compatible with a "single-pot" (pretreatment + saccharification), washfree bioprocessing approach $[25,26]$, use of lower IL concentration $(25-50 \%, \mathrm{w} / \mathrm{v})$ in water for biomass pretreatment that eliminates washing prior to enzymatic saccharification altogether [27,35], and the development of enzyme free, acid catalyzed IL hydrolysis process [36]. So far these alternative technologies are all limited to the labscale level of development and require more investigation before scale-up can occur.

\section{Scale-up of enzymatic hydrolysis}

Enzymatic hydrolysis at high solids loadings is another key to scale-up of lignocellulosic biochemical conversion processes, because of potentially higher sugar and ethanol titers and low hydraulic loads. However, high solids loading can pose rheological challenges, reduce mass and heat transfer efficiency, and increase the concentration of enzyme inhibitors in the system, resulting in lower conversion of glucan and xylan into fermentable sugars. Previous reports have simulated different operational scenarios and compared them in terms of productivity, yield, and numbers of stages and unit operation for materials from steam explosion, dilute acid, alkali pretreatment processes [19,37-41]. So far, there is limited information on large-scale enzymatic hydrolysis of IL pretreated material, especially at high solids loading as most of the saccharification data were obtained at laboratory scales with $1-2 \%$ loading of IL pretreated materials [16-18], which cannot be directly translated to industrially relevant scales. Thus, focused scale-up studies at high solid loadings are required to fit in the intermediate scale levels in the current study.

Figure 6 shows the typical fermentable sugar profile for a $72 \mathrm{~h}$ enzymatic saccharification of pretreated switchgrass at $10 \%$ solid loading in a $2 \mathrm{~L}$ reactor with $1.5 \mathrm{~L}$ working volume. It is observed that the concentrations of glucose, xylose and cellobiose increase rapidly in the first $30 \mathrm{mi}-$ nutes. The glucose concentration then continues to rapidly increase, whereas the xylose concentration follows a fairly steady increase until about $24 \mathrm{~h}$, and then a very slow, almost negligible increase up to $72 \mathrm{~h}$. The cellobiose level reached a plateau at $2 \mathrm{~h}$ and started to decrease after about $24 \mathrm{~h}$, indicating that the $\beta$-glucosidases are highly active and are not being inhibited by product formation. The rapid initial increase for all three sugar concentrations coincided with a significant reduction in biomass solubilization and slurry viscosity. This is attributed to the highly disrupted cellulose structure, increased porosity and accessibility in the IL pretreated fiber [7]. Furthermore, the easily solubilized xylo-oligosaccharides generated from the pretreated switchgrass promoted rapid xylose release, whereas the second stage of $x y-$ lan conversion, from approximately $3 \mathrm{~h}$ to $24 \mathrm{~h}$ reflects the hydrolysis of xylan polymers in the biomass. Unfortunately, this process essentially leveled off after $24 \mathrm{~h}$ with little further production of xylose in spite of the fact that only $65.0 \%$ of available xylan in the pretreated solids had been hydrolyzed. 


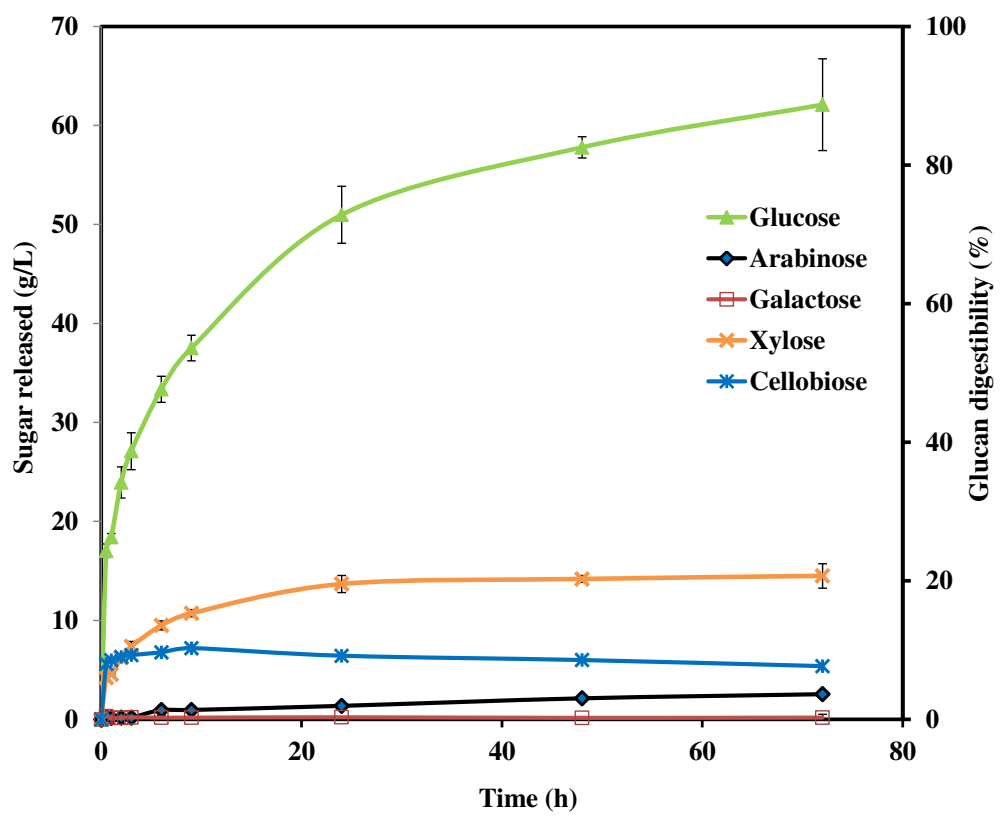

Figure 6 Sugar released from $2 \mathrm{~L}$ scale enzymatic hydrolysis of $\left[\mathrm{C}_{2} \mathrm{mim}\right][\mathrm{OAc}]$ pretreated switchgrass.

The evolution of glucose is more sustained, proceeding at a very fast kinetic rate from $1 \mathrm{~h}$ to $24 \mathrm{~h}$, and then at a relatively lower rate from 24 to $72 \mathrm{~h}$, at which point 99.8\% of available glucan in the IL pretreated solids has been hydrolyzed to glucose. High contents of glucose at $62.1 \mathrm{~g} / \mathrm{L}$ combined with $5.4 \mathrm{~g} / \mathrm{L}$ of cellobiose demonstrate high titers of sugar concentration. The glucan digestibility is consistent with previous reports demonstrating the equal effectiveness of $\left[\mathrm{C}_{2} \mathrm{mim}\right][\mathrm{OAc}]$ pretreatment at $3 \%$ loading and saccharification at $15 \%$ loading at small scales of 5 to $25 \mathrm{~mL}[16,18]$, suggesting a successful 60 fold scale up. However, the xylan digestibility was lower than that reported for small-scale studies, suggesting the following possibilities: 1 ) enzymes in the $\mathrm{HTec} 2$ cocktail may be deactivated/inhibited by residual $\left[\mathrm{C}_{2} \mathrm{mim}\right][\mathrm{OAc}]$ or end-product accumulation at high biomass loading, 2) $\left[\mathrm{C}_{2} \mathrm{mim}\right][\mathrm{OAc}]$ pretreatment at larger scales produces xylan that is less accessible to enzymes than the xylan produced at smaller scales. Thus further optimization of the enzyme cocktail may be required to obtain maximal sugar production.

\section{Mass balance and energy flow}

An analysis of the mass balance and energy flow of the ionic liquid pretreatment, the subsequent enzymatic saccharification, and their resultant composition of the products generated is summarized in Figure 7 to develop a clear overview of the technology scale up. On the $900 \mathrm{~g}$ basis of untreated switchgrass, $497.5 \mathrm{~g}$ of pretreated solids were recovered that retain $87.5 \%$ of glucan, $42.6 \%$ of xylan and $22.8 \%$ of lignin. On the same basis,
$25.2 \mathrm{~g}$ of glucose olignomers, $87.6 \mathrm{~g}$ of xylo-oligomers, plus 26.5 arabinan and $16.1 \mathrm{~g}$ of galactan, respectively, were recovered post hydrolysis. Approximately $322.8 \mathrm{~g}$ of glucose, 67.2 of xylose and $11.4 \mathrm{~g}$ of arabinose, respectively, were recovered from enzymatic hydrolysis of the recovered solids. Furthermore, of the $5100 \mathrm{~g}$ of ionic liquid used, $4721 \mathrm{~g}$ was detected in the liquid fraction and available for further recovery and recycling. A small portion of IL (6.5 g) was retained with pretreated switchgrass, and potentially posed inhibitory effects for the subsequent enzymatic hydrolysis and microbial fermentation. The overall IL balance closure is higher than $92 \%$.

The material balance indicates some mass loss during pretreatment and enzymatic hydrolysis, yet the overall glucose recovery in the liquid stream remains over $94 \%$, confirming that IL pretreatment can preserve most of the sugars and substantially enhance the effectiveness of enzymatic hydrolysis. The overall glucan balance closure on the basis of the recovered solids after pretreatment (95.0\%) is higher than xylan (77.1\%), which is attributed to the greater chemical robustness of glucose during the IL pretreatment [17]. A fraction of the hemicellulose remained in the liquid stream after pretreatment as well as in the residual solid after saccharification but is not lost to the overall conversion process [35]. During pretreatment, a significant amount of lignin was also solubilized into the liquid stream, causing the lignin reduction in the pretreated solids. However, the residual solids after enzymatic saccharification are also rich in lignin content, indicating potential opportunities for lignin valorization. For a long-term development of biorefinery, lignin supply will 


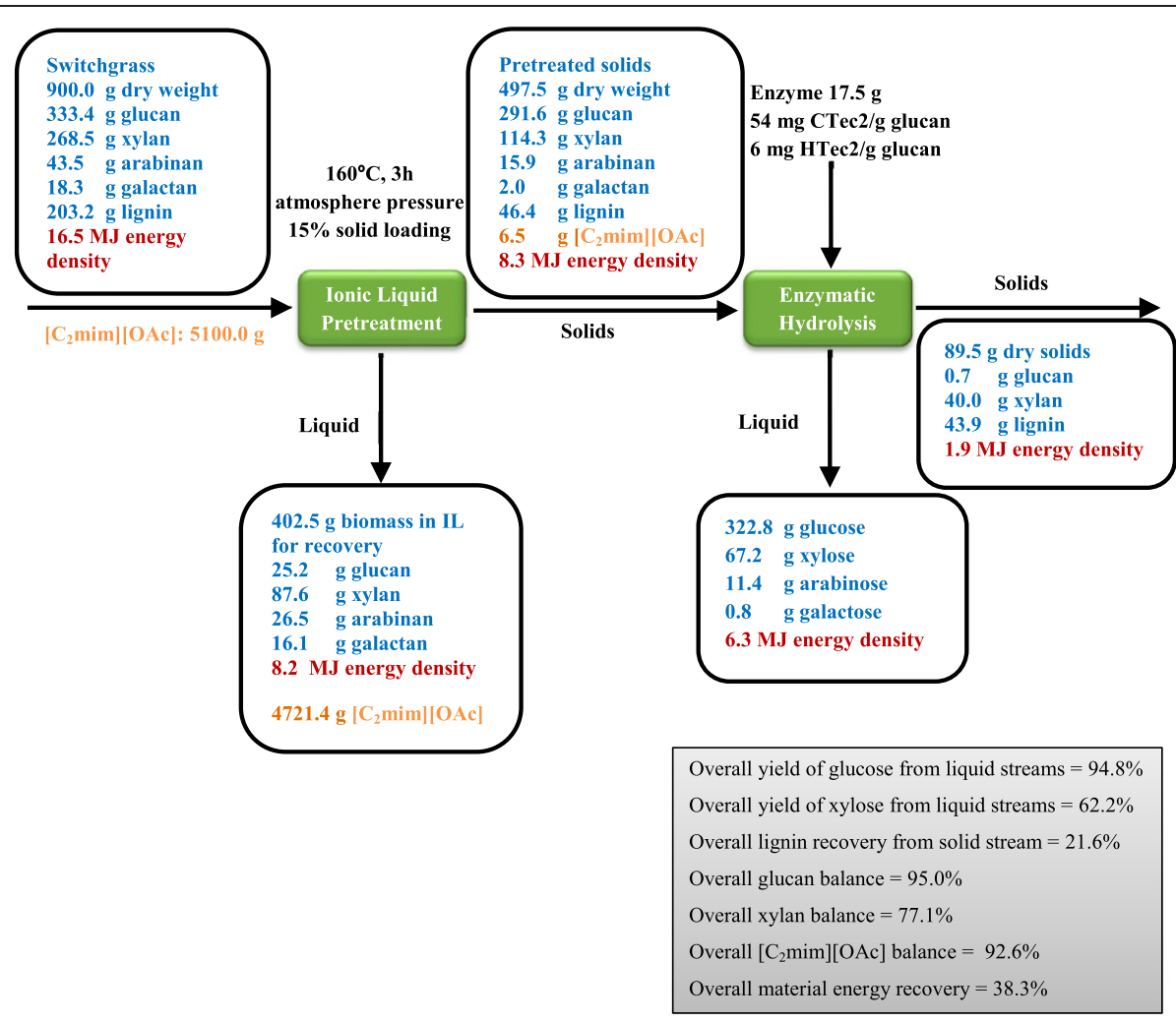

Figure 7 Mass balance and energy flow during $\left[C_{2}\right.$ mim] $[\mathrm{OAc}]$ pretreatment and subsequent enzymatic hydrolysis.

progressively increase as many types of lignocellulosic feedstocks are implemented in the future. Adding value to the lignin rich residue will significantly enhance the competitiveness of biomass-to-biofuels conversion [42].

One of the considerations that must be taken into account is the energy density of the feedstock itself. Energy density plays an important role in the overall energy and cost balance of the biofuel production process. A biomass feedstock with low energy density is less energy efficient to convert into a biofuel than one with a higher energy density due to the relatively high energy required for transportation, storage and distribution of the feedstock from the field to the biorefinery gate $[17,43,44]$. Lignin contains the higher energy content than cellulose and hemicellulose, and can be combusted to provide heat and/or power for the biorefinary process, and provide some excess power to generate additional revenue $[45,46]$. To understand how the IL pretreatment affects lignin recovery and energy flow, lignin content and energy density analysis of untreated, pretreated and saccharified switchgrass were conducted and are presented in Table 2. Results clearly show that, compared with $22.6 \%$ in untreated material, the lignin content was significantly decreased to $9.33 \%$ after IL pretreatment, however, after enzymatic hydrolysis, the residual solids are rich in lignin (49.08\%) due to the efficient conversion of polysaccharides into soluble sugars. Correspondingly, energy density of untreated $(18.37 \mathrm{KJ} / \mathrm{g})$, pretreated $(16.62 \mathrm{KJ} / \mathrm{g})$ and saccharified switchgrass $(21.72 \mathrm{KJ} / \mathrm{g})$ tracks well with their respective lignin content. Details about the energy density analysis and the relative correlation with three major components in various feedstocks are currently under investigation. The overall lignin recovery from solid stream is $21.6 \%$, indicating a large amount of lignin has dissolved in IL upon pretreatment and requires further separation. The material energy flow is also summarized in Figure 7 based on the energy density data from Table 2, and the overall recovery is $38.3 \%$ with high energy contents left in liquid stream, suggesting further energy recovery is highly warranted.

It should be addressed that due to their current high cost, recovery and recycle of ILs has been given more and more attentions for the requirements of commercial use in biomass pretreatment. These include using anti-

Table 2 Lignin content and energy density in three types of starting and recovered solids

\begin{tabular}{ccc}
\hline Biomass solids & Lignin (\%) & Energy density (KJ/g) \\
\hline Untreated & $22.58 \pm 1.01$ & $18.37 \pm 0.03$ \\
Pretreated & $9.33 \pm 0.38$ & $16.62 \pm 0.74$ \\
Saccharified & $49.08 \pm 1.46$ & $21.72 \pm 0.95$ \\
\hline
\end{tabular}


solvent such as acetone followed by distillation/evaporation for separation [9,47], biphasic system with addition of an aqueous solution containing kosmotropic anion, such as phosphate, carbonate or sulfate [48,49], and sequential membrane filtration and vacuum evaporation post sugar extraction from aqueous IL hydrolysate. Although these results show that separation and recovery of IL can be achieved by various methods, to date, all these potential alternatives have been limited to the labscale level of development and require more investigation before scale-up can occur. The process employed in the current report doesn't involve IL recovery, optimization for washing method, separation method, and removal of the remaining water, however, as a continuation of this study, JBEI and ABPDU are working together on the scale up demonstration of newly developed wash-free IL processes $[26,35]$ and liquid-liquid extraction and filtration based IL recycle technologies. The present work provides an essential first step to understand and evaluate the scale up effect and important parameters, and requires to be further developed for a commercially scalable and cost competitive process.

\section{Conclusions}

To the best of our knowledge, this is the first demonstration in the scientific literature for the scale-up of IL pretreatment by 600 -fold and subsequent enzymatic saccharification by 60 -fold at solid loadings up to $15 \%(\mathrm{w} / \mathrm{w})$. The results generated are consistent with those from the smallscale experiments that have been conducted at JBEI and elsewhere, and indicate there are no fundamental issues in terms of performance associated with the scale-up of an IL-based conversion technology. High solids loading during pretreatment and enzymatic hydrolysis offers several industrial advantages, including decreased reactor size, increased sugar titer and hydrolysis rate, and decreased water consumptions. The results also provide clear evidence of enzymatic inhibition, which is magnified by the fact that pretreated materials were not washed completely prior to hydrolysis, and thus, the inhibitors generated during pretreatment and washing will persist into hydrolysis and the downstream steps. Thus, the optimization and engineering of the IL tolerant enzyme cocktail and scale up design/operation of more effective IL pretreatment and post separation system must be realized before a commercially viable process is realized. The knowledge gained from this initial scale-up study is an essential first step in demonstrating the commercial viability of this promising pretreatment technology.

\section{Materials and methods Raw materials}

Switchgrass (Panicum virgatum) was kindly provided by Dr Putnam's lab at University of California, Davis. The samples were air dried first until the moisture was less than $10 \%$, and then grounded with Thomas Wiley Mill fitted with a $2 \mathrm{~mm}$ screen (Model 4, Arthur H. Thomas Co., Philadelphia, PA, USA). The samples were stored at $4^{\circ} \mathrm{C}$ cold room for use in all experimentation. The particle size distribution of this material after grinding was determined by following ASTM D1511-10 using a sieve shaker (Vibratory Sieve Shaker AS 200, Retsch, Newtown, PA, USA) and the biomass materials passing sieves of specific mesh sizes was measured (ASTM International, 2010). The majority of the materials by weight $(54 \%)$ have particle sizes ranging from 0.1 to $0.6 \mathrm{~mm}$. Cellulase (Cellic ${ }^{\circ} \mathrm{CTec}$ 2 ) and hemicellulase (Cellic $\left.{ }^{\circ} \mathrm{HTec} 2\right)$ were generously provided by Novozymes (Davis, CA). 1-Ethyl-3-methyl-limidazolium acetate $\left(\left[\mathrm{C}_{2} \mathrm{mim}\right][\mathrm{OAc}]\right)$, BASF, purity $\left.\geq 90 \%\right)$ was used as the ionic liquid for the pretreatment experiments. Trifluoroacetic acid (TFA), ethanol, acetic acid, sodium acetate, sulfuric acid, sodium hydroxide, and the monosaccharides including arabinose, galactose, xylose, glucose, and cellobiose were purchased from Sigma-Aldrich (St. Louis, MO).

\section{Reactor setup and operation for large scale IL pretreatment}

Optimal pretreatment temperature $\left(160^{\circ} \mathrm{C}\right)$ and residence time $(3 \mathrm{~h})$ using ionic liquid and switchgrass for fermentable sugar production were chosen from previous small scale studies $[7,15]$. In this scale up study, $15 \%(\mathrm{w} / \mathrm{w})$ biomass/IL solution was prepared by combining $900 \mathrm{~g}$ (dry basis) of switchgrass with $5.1 \mathrm{~kg}$ $\left[\mathrm{C}_{2} \mathrm{mim}\right][\mathrm{OAc}]$ in the $10 \mathrm{~L}$ Parr reactor (Model 4558, Parr Instrument Company, Moline, Illinois, USA) in triplicates. For each run, the reactor was sealed and the reactants were heated at $160^{\circ} \mathrm{C}$ for $3 \mathrm{~h}$ with a stirring speed of $50 \mathrm{rpm}$ from an anchor impellor. Temperature ramping (to $160^{\circ} \mathrm{C}$ ) and cooling (to $60^{\circ} \mathrm{C}$ ) times were approximately 30 and $20 \mathrm{~min}$, respectively. After $3 \mathrm{~h}$ incubation, the reactor was cooled down to $60^{\circ} \mathrm{C}$ with chilled water through the cooling coils inside the reactor. The reactor was open to sample 25 gram of biomass/IL slurry for viscosity measurement, and then $6 \mathrm{~L}$ of preheated hot water $\left(60^{\circ} \mathrm{C}\right)$ was slowly pumped into the reactor, causing precipitation of the biomass into large chunks. Both solids and liquids were transferred into a $50 \mathrm{~L}$ bucket for overnight soaking. This was followed by a 2-min homogenization step to obtain the uniform dispersion of small particles in the solutions with a laboratory blender (LBC 15, Waring Laboratory, Torrington, CT).

\section{Biomass washing}

The homogenized biomass was first separated from the IL-rich pretreatment liquid by filtration through cheese cloth $(100 \%$ natural bleached cotton fiber) at $25^{\circ} \mathrm{C}$ [50]. Then the recovered solids were washed and 
dewatered through cheesecloth to remove IL and dissolved byproducts such as lignin and hemicellulose that might inhibit enzymes in the subsequent enzymatic hydrolysis. The washing steps included 3 water washes $(12 \mathrm{~L}), 1$ ethanol wash $(6 \mathrm{~L}), 2$ ethanol/water $(1: 1, \mathrm{v} / \mathrm{v}, 6 \mathrm{~L})$ washes, and 1 final water wash $(12 \mathrm{~L})$ at room temperature. Each time water or ethanol was squeezed extensively from the biomass through cheesecloth [50]. All water wash effluent were collected separately and stored for further analysis of IL concentration and soluble sugar contents. The washed solids were collected to determine moisture content and calculate the solid recovery from IL pretreatment. About $10 \mathrm{~g}$ (dry basis) of the pretreated biomass was dried in the vacuum oven at $45^{\circ} \mathrm{C}$ to constant weight for composition and energy density analysis, and the rest was stored in sealed containers at $4^{\circ} \mathrm{C}$ for enzymatic hydrolysis.

\section{Chemical characterization of switchgrass}

Acid-insoluble lignin, and structural carbohydrates, i.e., glucan, xylan, arabinan and galactan, of switchgrass before and after pretreatment were determined according to analytical procedure of the National Renewable Energy Laboratory (NREL) by a two-step sulfuric acid hydrolysis [51,52]. Carbohydrates were analyzed by high performance anion exchange chromatography (HPAEC) on an ICS-3000 system (Dionex, Sunnyvale, CA), equipped with an electrochemical detector and a $4 \times 250 \mathrm{~mm}$ CarboPac PA20 analytical column. Elution was initiated with $97.2 \%(\mathrm{v} / \mathrm{v})$ water and $2.8 \%$ (v/v) $1 \mathrm{M} \mathrm{NaOH}$ for first $15 \mathrm{~min}$, with $20 \mu \mathrm{L}$ injection volume. Elute concentration was then switched to $55.0 \%(\mathrm{v} / \mathrm{v})$ water and $45.0 \%(\mathrm{v} / \mathrm{v}) 1 \mathrm{M} \mathrm{NaOH}$ for next $20 \mathrm{~min}$ and returned to $97.2 \%(\mathrm{v} / \mathrm{v})$ water and $2.8 \%(\mathrm{v} / \mathrm{v}) 1 \mathrm{M} \mathrm{NaOH}$ for the last $10 \mathrm{~min}$ to equilibrate the column. The flow rate was $0.5 \mathrm{~mL} / \mathrm{min}$. The monosaccharides including arabinose, galactose, xylose and glucose, were used as the external standards for HPAEC and prepared at levels of 0 to $100 \mathrm{mM}$ before use. Absorbance reading of acid soluble lignin was taken at $205 \mathrm{~nm}$ using a UV-Vis spectrophotometer (Shimadzu UV-2401) with high purity quartz cuvettes with a $1 \mathrm{~cm}$ pathlength. The extinction coefficient of $110 \mathrm{~L} / \mathrm{g} \mathrm{cm}$ was used for the calculation of acid soluble lignin for switchgrass [53].

To obtain the sugar balance from dissolution of hemicelluloses during IL pretreatment, a TFA hydrolysis was performed. The supernatants from the water wash steps were collected and concentrated, $30 \mu \mathrm{L}$ of solution was diluted 10-fold with water and treated with $150 \mu \mathrm{L}$ of TFA at $120^{\circ} \mathrm{C}$ for $1 \mathrm{~h}$. The hydrolyzed solution was centrifuged at 10,000 $\mathrm{g}$ for $10 \mathrm{~min}$, and the supernatant was analyzed using HPAEC for the monosaccharide analysis after evaporation of the TFA residues in a Centri-Vap Vacuum Concentrator (Labconco Corp, $\mathrm{MO}$ ) at $30^{\circ} \mathrm{C}$ overnight.

\section{Large scale enzymatic saccharification}

To investigate the washing efficiency on the IL removal in the recovered solids and the effect of IL content on enzymatic saccharification, a small scale study was first conducted by hydrolyzing the solid samples recovered from each washing step. The experiments were run at $2 \%(\mathrm{w} / \mathrm{w})$ in duplicate at $50^{\circ} \mathrm{C}$ and $150 \mathrm{rpm}$ in a reciprocating shaker. The total batch volume was $25 \mathrm{~mL}$ with cellulase (CTec2) concentration of $54 \mathrm{mg}$ protein/g glucan and endoxylanase (HTec2) concentration of $6 \mathrm{mg}$ protein/g glucan to ensure fast hydrolysis. The protein concentrations of the two commercial enzyme mixtures (CTec2 $190 \mathrm{~g} / \mathrm{L}, \mathrm{HTec} 2$ $174 \mathrm{~g} / \mathrm{L}$ ) were determined by the Bradford assay (BioRad, Hercules, CA) using bovine serum albumin as a standard.

After $72 \mathrm{~h}$, the hydrolysates were analyzed on HPAEC for the monosaccharides release and their correlation with IL contents. For the scale up experiment of enzymatic hydrolysis, the IL pretreated switchgrass samples from final washing step were fed into 2 L IKA reactor (IKA LR-2.ST, IKA Works, Wilmington, NC) in triplicates. The samples were kept at $10 \%(\mathrm{w} / \mathrm{w})$ biomass loading in water with a working volume of $1.5 \mathrm{~L}$ and continuously mixed at $150 \mathrm{rpm}$ for enzymatic hydrolysis using an anchor impeller. The Novozymes cocktails were added into each reactor with cellulase (CTec2) concentration of $54 \mathrm{mg}$ protein/g glucan and endoxylanase (HTec2) concentration of $6 \mathrm{mg}$ protein/g glucan. The reaction was monitored by taking samples from 0 , $0.5,1,2,3,6,9,24,48$ and $72 \mathrm{~h}$ of time intervals and measuring monomeric sugar production. After the hydrolysis time elapsed, the hydrolysates were immediately transferred into the plastic containers and placed at $4{ }^{\circ} \mathrm{C}$ to avoid further reaction.

\section{IL measurement}

The $\mathrm{C}_{2} \mathrm{mim}^{+}$content was determined using a Dionex UltiMate 3000 UHPLC (Dionex, Sunnyvale, CA) with UV-vis detecter at $240 \mathrm{~nm}$ wavelength. A Dionex acclaim $120 \mathrm{C} 18$ column achieved the separation by isocratic elution with a mobile phase consisting of $20 \mathrm{mM}$ ammonium acetate and $1 \%$ acetic acid at $1.0 \mathrm{~mL} / \mathrm{min}$ and $20^{\circ} \mathrm{C}$. The IL supernatant taken from various washing steps were directly measured for IL content after proper dilutions. To measure the residual $\left[\mathrm{C}_{2} \mathrm{mim}\right][\mathrm{OAc}]$ remaining in the biomass after various wash steps, the recovered solids were saccharified for 120 hours using an extreme excess of enzymes $(540 \mathrm{mg} / \mathrm{g}$ glucan of CTec2, $300 \mathrm{mg} / \mathrm{g}$ glucan of $\mathrm{HTec} 2)$ at $50^{\circ} \mathrm{C}$ and $\mathrm{pH} 5.5$ to completely solubilize the solids and ensure the $\left[\mathrm{C}_{2} \mathrm{mim}\right][\mathrm{OAc}]$ attached to the solids went into the liquid fraction. Then the liquid samples were diluted and measured on HPLC for $\left[\mathrm{C}_{2} \mathrm{mim}\right][\mathrm{OAc}]$ content. 


\section{Viscosity measurement}

The rheological properties of switchgrass-IL slurry were investigated for samples before pretreatment, after pretreatment, and after pretreatment and washing (removal of IL) using stress controlled Malvern Kinexus Rheometer (Worcestershire, UK) a with $40 \mathrm{~mm}$ diameter parallel plate geometry. A gap height of $5 \mathrm{~mm}$ was used and care was taken to avoid air bubbles being trapped in the sample by obtaining a bulge of the sample at the edges of the plate. Oscillatory stress sweeps were conducted at $25^{\circ} \mathrm{C}$ from 0.01 to $1000 \mathrm{~Pa}$ under a constant frequency of $5 \mathrm{~Hz}$. A clear viscoelastic region was observed between 1 and $100 \mathrm{~Pa}$. Accordingly, an oscillatory frequency sweep was conducted at $25^{\circ} \mathrm{C}$ between 0.01 to $150 \mathrm{~Hz}$ at a constant stress of $10 \mathrm{~Pa}$. Viscoelastic properties including elastic modulus (G', Pa), viscous modulus (G', Pa), and complex viscosity $(\eta *$ Pa-s) were measured and reported in this study.

\section{Energy density measurement}

The solid samples before and after IL pretreatment were subjected to a standard bomb calorimeter (C2000 Oxygen Bomb Calorimeter, IKA Works, Wilmington, NC) for energy density measurement. All samples were dried in a vacuum oven at $40^{\circ} \mathrm{C}$ until the moisture content is lower than $4 \%$, ball milled to pass a 20 mesh screen and then compressed into pellets using a hydraulic pelletizer (MTI $12 \mathrm{~T}$ pelletizer, MTI, Richmond, CA) prior to being weighed. Heat content was determined by burning the samples with excess of oxygen at a pressure of $435 \mathrm{psi}$ in a sealed steel bomb, which is regarded as a near-adiabatic system.

\section{Abbreviations \\ IL: Ionic liquid; JBEl: Joint bioenergy institute; ABPDU: Advanced biofuels process demonstration unit; $\left[\mathrm{C}_{2} \mathrm{mim}\right][\mathrm{OAc}]$ : 1-ethyl-3-methylimidaolzium acetate; HPAEC: High performance anion exchange chromatography; TFA: Trifluoroacetic acid; NREL: National renewable energy laboratory.}

\section{Competing interests}

The authors declare that they have no competing interests.

\section{Authors' contributions}

$\mathrm{CL}$ and DT conducted the pretreatment and saccharification experiments. $\mathrm{CL}$ conducted data analysis and drafted the manuscript. DT carried out the viscosity measurement and contributed to the viscosity related part of the manuscript. WH and JLG performed the energy density and IL measurement. JW performed the compositional and hydrolysate analysis. SS, BAS and KS contributed to the original experimental design and modifications of the draft. SS, BAS, JLG and KS coordinated and supervised the collaboration project. All authors read and approved the final manuscript.

\section{Acknowledgements}

ABPDU would like to acknowledge the funding support from Office of Biomass Program within the US DOE's Office of Energy Efficiency and Renewable Energy, and also the funding support from the American Recovery and Reinvestment Act. JBEI would like to acknowledge the funding support from US DOE's Office of Science, Office of Biological and Environmental Research, through contract DE-AC02-05CH11231 between Lawrence Berkeley National Laboratory and the US DOE. The authors would like to thank the Laboratory of Dr. Daniel Putnam from the University of
California at Davis for providing the switchgrass, and Novozymes for the gift of the enzyme cocktails used in this work.

\section{Author details}

${ }^{1}$ Advanced Biofuels Process Demonstration Unit, Lawrence Berkeley National Laboratory, Emeryville, CA, USA. ${ }^{2}$ Deconstruction Division, Joint BioEnergy Institute, Emeryville, CA, USA. ${ }^{3}$ Biological and Materials Science Center, Sandia National Laboratories, Livermore, CA, USA.

\section{Received: 20 May 2013 Accepted: 7 October 2013}

Published: 25 October 2013

\section{References}

1. Johnson JM, Coleman MD, Gresch R, Jaradat A, Mitchell R, Reicosky D, Wilhelm WW: Biomass-bioenergy crops in the united states: a changing paradigm. Am J Plant Sci Biotechnol 2007, 1(1):1-28.

2. Alvira P, Tomás-Pejó E, Ballesteros M, Negro MJ: Pretreatment technologies for an efficient bioethanol production process based on enzymatic hydrolysis: a review. Bioresour Technol 2010, 101(13):4851-4861.

3. Banerjee G, Car S, Liu TJ, Williams DL, Meza SL, Walton JD, Hodge DB: Scaleup and integration of alkaline hydrogen peroxide pretreatment, enzymatic hydrolysis, and ethanolic fermentation. Biotechnol Bioeng 2012, 109(4):922-931.

4. Modenbach AA, Nokes SE: The use of high-solids loadings in biomass pretreatment-a review. Biotechnol Bioeng 2012, 109(6):1430-1442.

5. Yang B, Dai Z, Ding S-Y, Wyman CE: Enzymatic hydrolysis of cellulosic biomass. Biofuels 2011, 2(4):421-450.

6. Dadi AP, Varanasi S, Schall CA: Enhancement of cellulose saccharification kinetics using an ionic liquid pretreatment step. Biotechnol Bioeng 2006, 95(5):904-910.

7. Li C, Knierim B, Manisseri C, Arora R, Scheller HV, Auer M, Vogel KP, Simmons BA, Singh S: Comparison of dilute acid and ionic liquid pretreatment of switchgrass: biomass recalcitrance, delignification and enzymatic saccharification. Bioresour Technol 2010, 101(13):4900-4906.

8. Singh S, Simmons BA, Vogel KP: Visualization of biomass solubilization and cellulose regeneration during ionic liquid pretreatment of switchgrass. Biotechnol Bioeng 2009, 104(1):68-75.

9. Sun N, Rahman M, Qin Y, Maxim ML, Rodriguez H, Rogers RD: Complete dissolution and partial delignification of wood in the ionic liquid 1-ethyl3-methylimidazolium acetate. Green Chem 2009, 11(5):646-655.

10. Lee SH, Doherty TV, Linhardt RJ, Dordick JS: Ionic liquid-mediated selective extraction of lignin from wood leading to enhanced enzymatic cellulose hydrolysis. Biotechnol Bioeng 2009, 102(5):1368-1376.

11. Li C, Cheng G, Balan V, Kent MS, Ong M, Chundawat SPS, Sousa L, Melnichenko YB, Dale BE, Simmons BA, et al: Influence of physico-chemical changes on enzymatic digestibility of ionic liquid and AFEX pretreated corn stover. Bioresour Technol 2011, 102(13):6928-6936.

12. Tan SSY, MacFarlane DR, Upfal J, Edye LA, Doherty WOS, Patti AF, Pringle $J M$, Scott JL: Extraction of lignin from lignocellulose at atmospheric pressure using alkylbenzenesulfonate ionic liquid. Green Chem 2009, 11(3):339-345.

13. Sun $L$, Li C, Xue Z, Simmons BA, Singh S: Unveiling high-resolution, tissue specific dynamic changes in corn stover during ionic liquid pretreatment. RSC Adv 2013, 3(6):2017-2027.

14. Cheng G, Varanasi P, Li CL, Liu HB, Menichenko YB, Simmons BA, Kent MS, Singh S: Transition of cellulose crystalline structure and surface morphology of biomass as a function of ionic liquid pretreatment and its relation to enzymatic hydrolysis. Biomacromolecules 2011, 12(4):933-941.

15. Arora R, Manisseri C, Li C, Ong M, Scheller HV, Vogel K, Simmons BA, Singh $S$ : Monitoring and analyzing process streams towards understanding ionic liquid pretreatment of switchgrass (Panicum virgatum L.). BioEnergy Research 2010, 3:134-145.

16. Li C, Sun L, Simmons B, Singh S: Comparing the recalcitrance of eucalyptus, pine, and switchgrass using ionic liquid and dilute acid pretreatments. BioEnergy Research 2013, 6(1):14-23.

17. Shi J, Thompson VS, Yancey NA, Stavila V, Simmons BA, Singh S: Impact of mixed feedstocks and feedstock densification on ionic liquid pretreatment efficiency. Biofuels 2013, 4(1):63-72.

18. Wu H, Mora-Pale M, Miao J, Doherty TV, Linhardt RJ, Dordick JS: Facile pretreatment of lignocellulosic biomass at high loadings in room temperature ionic liquids. Biotechnol Bioeng 2011, 108(12):2865-2875. 
19. Di Risio S, Hu CS, Saville BA, Liao D, Lortie J: Large-scale, high-solids enzymatic hydrolysis of steam-exploded poplar. Biofuels Bioprod Biorefin 2011, 5(6):609-620.

20. Dibble DC, Li CL, Sun L, George A, Cheng ARL, Cetinkol OP, Benke P, Holmes BM, Singh S, Simmons BA: A facile method for the recovery of ionic liquid and lignin from biomass pretreatment. Green Chem 2011, 13(11):3255-3264.

21. Fu D, Mazza G: Aqueous ionic liquid pretreatment of straw. Bioresour Technol 2011, 102(13):7008-7011.

22. Ouellet M, Datta S, Dibble DC, Tamrakar PR, Benke PI, Li C, Singh S, Sale KL, Adams PD, Keasling JD, et al: Impact of ionic liquid pretreated plant biomass on Saccharomyces cerevisiae growth and biofuel production. Green Chem 2011, 13(10):2743-2749.

23. Kim Y, Ximenes E, Mosier NS, Ladisch MR: Soluble inhibitors/deactivators of cellulase enzymes from lignocellulosic biomass. Enzyme Microb Technol 2011, 48(4-5):408-415.

24. Qi BK, Chen XR, Wan YH: Pretreatment of wheat straw by nonionic surfactant-assisted dilute acid for enhancing enzymatic hydrolysis and ethanol production. Bioresour Technol 2010, 101(13):4875-4883.

25. Park Jl, Steen EJ, Burd H, Evans SS, Redding-Johnson AM, Batth T, Benke PI, D'Haeseleer P, Sun N, Sale KL, et al: A thermophilic ionic liquid-tolerant cellulase cocktail for the production of cellulosic biofuels. Plos One 2012, 7(5):e37010.

26. Shi J, Gladden J, Sathitsuksanoh N, Kambam P, Sandavol L, Mitra D, Zhang S, Singer S, George A, Simmons B, et al: One-pot ionic liquid pretreatment and saccharification of switchgrass. Green Chem 2013.

27. Fu DB, Mazza G: Optimization of processing conditions for the pretreatment of wheat straw using aqueous ionic liquid. Bioresour Technol 2011, 102(17):8003-8010.

28. Cruz A, Scullin C, Mu C, Cheng G, Stavila V, Varanasi P, Xu D, Mentel J, Chuang Y-D, Simmons $B$, et al: Impact of high biomass loading on ionic liquid pretreatment. Biotechnology for Biofuels 2013, 6(1):52

29. Sathitsuksanoh N, Zhu ZG, Wi S, Zhang YHP: Cellulose solvent-based biomass pretreatment breaks highly ordered hydrogen bonds in cellulose fibers of switchgrass. Biotechnol Bioeng 2011, 108(3):521-529.

30. Aaltonen $\mathrm{O}$, Jauhiainen $\mathrm{O}$ : The preparation of lignocellulosic aerogels from ionic liquid solutions. Carbohydr Polym 2009, 75(1):125-129.

31. Stickel JJ, Knutsen JS, Liberatore MW, Luu W, Bousfield DW, Klingenberg DJ, Scott CT, Root TW, Ehrhardt MR, Monz TO: Rheology measurements of a biomass slurry: an inter-laboratory study. Rheol Acta 2009, 48(9):1005-1015.

32. Wiman M, Palmqvist B, Tornberg E, Liden G: Rheological characterization of dilute acid pretreated softwood. Biotechnol Bioeng 2011, 108(5):1031-1041.

33. Viamajala S, McMillan JD, Schell DJ, Elander RT: Rheology of corn stover slurries at high solids concentrations - effects of saccharification and particle size. Bioresour Technol 2009, 100(2):925-934.

34. Brennan TCR, Datta S, Blanch HW, Simmons BA, Holmes BM: Recovery of sugars from ionic liquid biomass liquor by solvent extraction. BioEnergy Research 2010, 3(2):123-133.

35. Sun N, Liu H, Sathitsuksanoh N, Stavila V, Sawant M, Bonito A, Tran K, George A, Sale K, Singh S, et al: Production and extraction of sugars from switchgrass hydrolyzed in ionic liquids. Biotechnology for Biofuels 2013, 6(1):39.

36. Binder J, Raines R: Fermentable sugars by chemical hydrolysis of biomass. Proc Natl Acad Sci U S A 2010, 107:4516-4521.

37. Yang J, Zhang XP, Yong QA, Yu SY: Three-stage enzymatic hydrolysis of steam-exploded corn stover at high substrate concentration. Bioresour Technol 2011, 102(7):4905-4908.

38. Ouyang J, Li ZJ, Li X, Ying HJ, Yong Q: Enhanced enzymatic conversion and glucose production via two-step enzymatic hydrolysis of corncob residue from xylo-oligosaccharides producer's waste. BioResources 2009, 4(4):1586-1599.

39. Thomsen MH, Thygesen A, Jorgensen $\mathrm{H}$, Larsen J, Christensen $\mathrm{BH}$, Thomsen $A B$ : Preliminary results on optimization of pilot scale pretreatment of wheat straw used in coproduction of bioethanol and electricity. Appl Biochem Biotechnol 2006, 130(1-3):448-460.

40. Martin C, Thomsen MH, Hauggaard-Nielsen H, BelindaThomsen A: Wet oxidation pretreatment, enzymatic hydrolysis and simultaneous saccharification and fermentation of clover-ryegrass mixtures. Bioresour Technol 2008, 99(18):8777-8782.

41. Zhang Y, Liu YY, Xu JL, Yuan ZH, Qi W, Zhuang XS, He MC: High solid and low enzyme loading based saccharification of agricultural biomass. BioResources 2012, 7(1):345-353.
42. Varanasi $P$, Singh $P$, Auer $M$, Adams $P$, Simmons $B$, Singh S: Survey of renewable chemicals produced from lignocellulosic biomass during ionic liquid pretreatment. Biotechnology for Biofuels 2013, 6(1):14

43. Sokhansanj S, Mani S, Turhollow A, Kumar A, Bransby D, Lynd L, Laser M: Large-scale production, harvest and logistics of switchgrass (Panicum virgatum L.) - current technology and envisioning a mature technology. Biofuel Bioprod Bior 2009, 3(2):124-141.

44. Sokhansanj S, Hess JR: Biomass supply logistics and infrastructure \#. T Biofuels 2009, 581:1-25.

45. Novaes E, Kirst M, Chiang V, Winter-Sederoff H, Sederoff R: Lignin and biomass: a negative correlation for wood formation and lignin content in trees. Plant Physiol 2010, 154(2):555-561.

46. Mendu V, Shearin T, Campbell JE, Stork J, Jae J, Crocker M, Huber G, DeBolt S: Global bioenergy potential from high-lignin agricultural residue. Proc Natl Acad Sci U S A 2012, 109(10):4014-4019.

47. Dibble D, Li C, Sun L, George A, Cheng A, Cetinkol O, Benke P, Holmes B, Singh S, Simmons B: A facile method for the recovery of ionic liquid and lignin from biomass pretreatment. Green Chem 2011, 13:3255-3264.

48. Gutowski K, Grant A, Willauer H, Huddleston J, Swatloski R, Holbrey J, Rogers $R$ : Controlling the aqueous miscibility of ionic liquids: aqueous biphasic systems of water-miscible ionic liquids and water-structuring salts for recycle, metathesis, and separations. J Am Chem Soc 2003, 125:6632-6633.

49. Shill K, Padmanabhan S, Xin Q, Prausnitz JM, Clark DS, Blanch HW: Ionic liquid pretreatment of cellulosic biomass: enzymatic hydrolysis and ionic liquid recycle. Biotechnol Bioeng 2011, 108(3):511-520.

50. Abbas C, Beery K, Dennison E, Corrington P: Thermochemical Treatment, Separation, and Conversion of Corn Fiber to Ethanol. In Lignocellulose Biodegradation. vol. 889. American Chemical Society; 2004:84-97.

51. Sluiter A, Hames B, Ruiz R, Scarlata C, Sluiter J, Templeton D: Determination of structural carbohydrates and lignin in biomass.LAP-002 NREL analytical procedure. Golden, CO: National Renewable Energy Laboratory; 2004.

52. Sluiter A, Hames B, Ruiz R, Scarlata C, Sluiter J, Templeton D: Determination of ash in biomass: LAP-005 NREL analytical procedure. Golden, CO: National Renewable Energy Laboratory; 2004

53. Suryawati L, Wilkins MR, Bellmer DD, Huhnke RL, Maness NO, Banat IM: Effect of hydrothermolysis process conditions on pretreated switchgrass composition and ethanol yield by SSF with Kluyveromyces marxianus IMB4. Process Biochem 2009, 44(5):540-545.

doi:10.1186/1754-6834-6-154

Cite this article as: Li et al:: Scale-up and evaluation of high solid ionic liquid pretreatment and enzymatic hydrolysis of switchgrass. Biotechnology for Biofuels 2013 6:154

\section{Submit your next manuscript to BioMed Central and take full advantage of:}

- Convenient online submission

- Thorough peer review

- No space constraints or color figure charges

- Immediate publication on acceptance

- Inclusion in PubMed, CAS, Scopus and Google Scholar

- Research which is freely available for redistribution 